\title{
Multi-Level and Generic Decisional Model for E-Governance Applications in the Educational Field
}

\author{
Kele Mbbe Ripaul Carlos ${ }^{1}$ Nkenlifack Marcellin Julius ${ }^{2}$ and Kamla Vivien Corneille ${ }^{3}$ \\ PhD Scholar ${ }^{1}$ and Professor ${ }^{2-3}$ \\ ${ }^{1}$ Faculty of Science, University of Ngaoundéré, Cameroon \\ ${ }^{2}$ LAIA - Faculty of Science, University of Dschang, Cameroon \\ ${ }^{3}$ Dept. of Mathematics and Computer Science, ENSAI, University of Ngaoundéré, Cameroon
}

\begin{abstract}
This article presents the mechanisms to create a generic platform for decision makers to implement rapid management models, with a multi-scale and multi-level stratification of education, including basic education, secondary and higher education, while minimizing the risk of errors, so as to increase their efficiency in the governance field. We will identify beforehand the various active and passive element involved in an education system, considered here as the model levels and the various interactions between them. Then we list the specific objectives considered in the model. We will build on the analysis and knowledge management techniques to develop a multi-level decision model incorporating levels and expected or desired objectives for better decision making.

This work will help to solve the difficulties that governments sometimes face in optimizing and taking decision making regarding construction of schools or universities with possibly building of a platform for e-learning in various localities, assignment of teachers or non-teaching staff in an institution, training of these as needed, allocation of teaching materials, benches and laboratory equipment. It is for us to truly put technology at the service of governance in education, and development in general.
\end{abstract}

Key Words: E-governance, Education, e-learning, Decision support system, Platform, Generic model, Meta modeling, Knowledge management.

\section{INTRODUCTION}

The term "governance" comes from the Greek verb "kubernan" which means "to pilot a ship or a tank". Used by Plato, this term was used in French as a synonym for "government" until the end of the eighteenth century to be taken over in the English sense "governance" in the 80s [1]. The World Bank defines it as the set of traditions and institutions by which power is exercised in a country for the benefit of all. This definition is interesting in that it links the exercise of power to the search for the common good. The European Commission, for its part, offers a definition adapted to the European development context, but which offers a certain potential for generalizing its use. Thus, for this institution: "The notion of" governance "refers to the rules, processes and behaviors that influence the exercise of powers at the European level, particularly from the point of view of openness, participation, responsibility, efficiency and coherence "[2]. It is based on five fundamental principles [3]:

- The legitimacy of the exercise of power and rooting,

- Conformity to the democratic ideal and the exercise of citizenship,

- Competence and efficiency,

- The relations between the local and the global, between the scales of governance.

Electronic governance is defined as "the use of information and communication technologies (ICT) in public administrations, coupled with changes in the organization and new skills of staff" [4]. Thus, ICTs are associated with "technical devices having as constituents information processing apparatuses and having the social effect of circulating messages and, thereby, making possible exchanges of information, interpretations, production of knowledge and knowledge in society "[5]. They are an essential tool that 
we cannot do without every day in various sectors of our world namely: communication, transport, health, education, economy, banking etc. Each of these sectors is run by an administration in one state; it must be made efficient and productive.

Education is the sector that matters most to us in this article; it plays a vital role in the life of every citizen. Education is therefore an essential right, which allows everyone to receive education and flourish in their social life, and is therefore vital for the economic, social and cultural development of all societies [6]. It is for this reason that we need to define a multi-level model that allows policymakers to make decisions on e-governance in the field of education.

To achieve this, we present the different elements involved in an education system because they are considered as the input parameters of the model, as well as the different interactions between them. We also present the objectives to be achieved; they are considered as outputs in the model.

The sequel is composed of the second section which presents a brief overview of the importance of e-governance as well as the decision-making models of e-governance in the field of education, the third section which presents the model itself and finally the fourth section concludes and presents perspectives

\section{REVIEW OF THE LITERATURE}

\subsection{Importance of ICT in the implementation of e-governance}

Information and communication technologies refer to a set of technologies based on information technology, microelectronics, telecommunications (especially networks), multimedia and audio-visual, which, when combined and interconnected, allow to search, store, process and transmit information, in the form of data of various types (text, sound, still images, video images, etc.), and allow interactivity between people, and between people and machines [7].

According to the previous definition, we see that ICT is a very important tool for our society; we find them everywhere in everyday life:

- $\quad$ in telecommunications (call centers, mobile telephony, GPS, etc.),

- in electronics (components, consumer equipment, televisions, DVD players, etc.), in the Internet (servers, networks, consulting, troubleshooting ...);

- In Education, we have the following ICT applications (Tutorial, Online Learning, Digital Work Spaces (ENT) or Digital Learning Spaces (ENA), Interactive Whiteboard (IWB)) ;

- $\quad$ in health, we have the computerized medical file;

- $\quad$ in the economy we can cite e-commerce or e-commerce, online banking, online insurance;

- in the field of transport we can mention the interactive terminal which is a computer terminal made available to the public to provide access to information networks and geolocation;

- $\quad$ in the field of the environment we have sustainable computing or green computation or green IT;

- $\quad$ in the administration, with applications such as electronic voting, tax tele-declaration, the official journal, e-governance (electronic governance).

A real societal challenge, Information and Communication Technologies (ICT) are a factor of economic development, competitiveness, job creation and the diffusion of knowledge. By facilitating access to knowledge, the Internet is a powerful tool for development, education and training. Public services have a significant impact on economic and social life at the national level. It is essential to offer these services in an integrated, transparent and secure way. This requires effective use of ICTs. ICT development must therefore respond to the evolution of society and the real needs of users. It must be able to manage the data, while ensuring the security of information and processes; this requires an in-depth modernization of administrations. To this end, the use of ICTs is essential and makes it possible to act on the processes, in order to make them more efficient, totally oriented towards the internal users, the citizens and the company. They are therefore used by governments to transform the public sector by improving its transparency, efficiency, access to public services and citizen participation [8]: hence e-governance.

\subsection{The importance of e-governance in a country}

E-governance or e-governance aims to make government or administration more accountable, transparent and effective; this has a direct impact on the improvement of public services [8]. Electronic governance therefore increases the efficiency of the administration's services. Electronic administration improves the internal organization of services. It enables the automation of simple and repetitive tasks, thus freeing up time for tasks that are more rewarding for the employee and create added value. Egovernment promotes transversal work and the networking of partners. It makes the action of authority visible to its citizens and ensures proximity to the field, thereby strengthening the social bond. E-government also generates savings and allows the pooling of resources to respond to changes in the environment (regulations, etc.) in terms of human and financial resources. Several challenges are to be taken up by the governors with regard to electronic governance to know [8]:

- Courage and political will to propose a new model of the administration and its organs,

- Development of a training and support program for full public service membership,

- The establishment of national structuring projects in the field of: Public OpenData, Web Accessibility ... 
- Achieving an environment of trust (securing the use of ICT for transactions on a sound legal framework, ensuring the protection of personal information used and ensuring the security of electronic exchanges).

In addition to these challenges, there are improvements to be made in many aspects of societal life [8]:

- Policies,

- Legal and regulatory,

- Administrative and organizational,

- Technological,

- Educational, aimed at raising the awareness of public service users online, upgrading of civil servants, training and development of ICT skills of future graduates of the University.

For the latter, it is important to stress that governments must play a vital role in providing education to the people, and "education for all" as a central focus of the Millennium Development Goals with a focus to be placed on ICT learning. It is in this sense that several decision-making models in the field of e-governance in education have been developed.

\subsection{Decision-making models for e-governance in education}

\subsubsection{The model ASPID}

The ASPID model [9] (adoption, substitution, progress, innovation ... deterioration) aims to model the process of adoption and pedagogical integration of technologies in an educational context. ASPID has been inspired by surveys of more than 50,000 students and teachers over the last 10 years, as well as some 1,500 hours of classroom observations where various technologies are used: laptop, iPad, touch pad, interactive whiteboard, smart phone, etc. These observations were also made in various kindergarten teaching contexts at the University and on several continents.

All phases of this model are related to the teacher's level of collaborative techno-pedagogical engagement. Nevertheless, it is important to understand that increased engagement will not necessarily lead to the highest level. This commitment must also be reflected, be done by collaborating with its peers (to learn and learn), by listening to its learners, by learning about the latest advances in the field of technology in education, and this, in order to really be able to evolve in his practice. Finally, a model for the adoption and pedagogical integration of technologies in an educational context cannot be complete without taking into account the degree of responsible use of technology by learners for learning purposes. In other words, according to the ASPID model, it is imperative to:

- $\quad$ to seek to progress as a teacher towards the INNOVATION level;

- $\quad$ to ensure that all learners use technology more and more, responsibly, and to learn. Figure 2 illustrates the ASPID model.

Several other models have been developed like ADDIE model and simulation models.

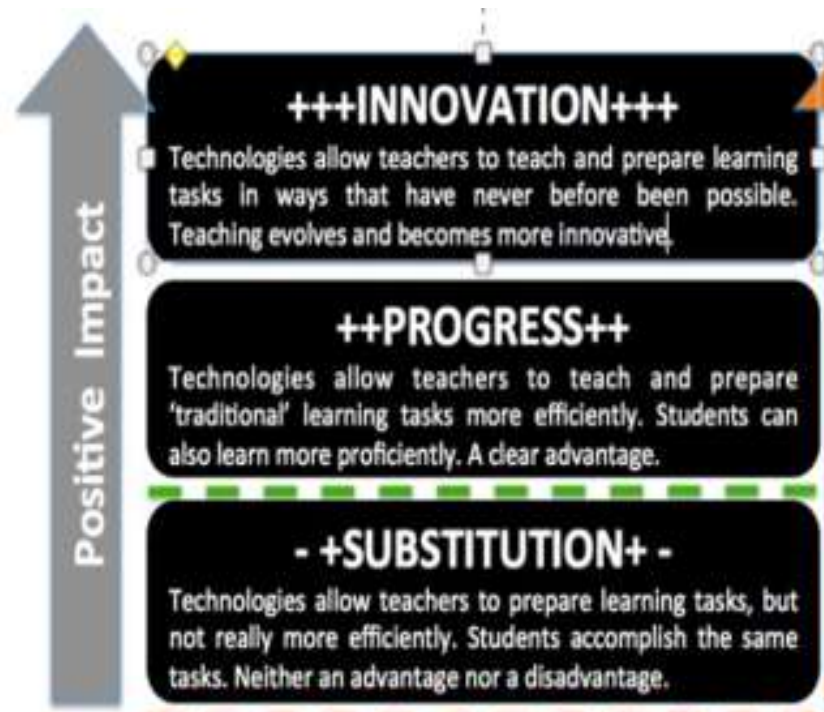

\section{+++INNOVATION++t}

the have never before been possibe.

asks in ways that have never before been possible.

\section{++PROGRESS++}

'tradilional' learning tasks more efficiently. Students can

also learn more proficiently. A clear advantage.

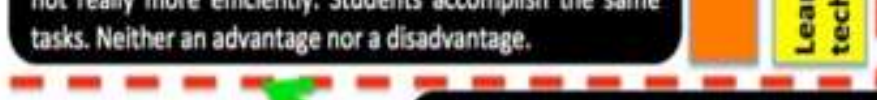

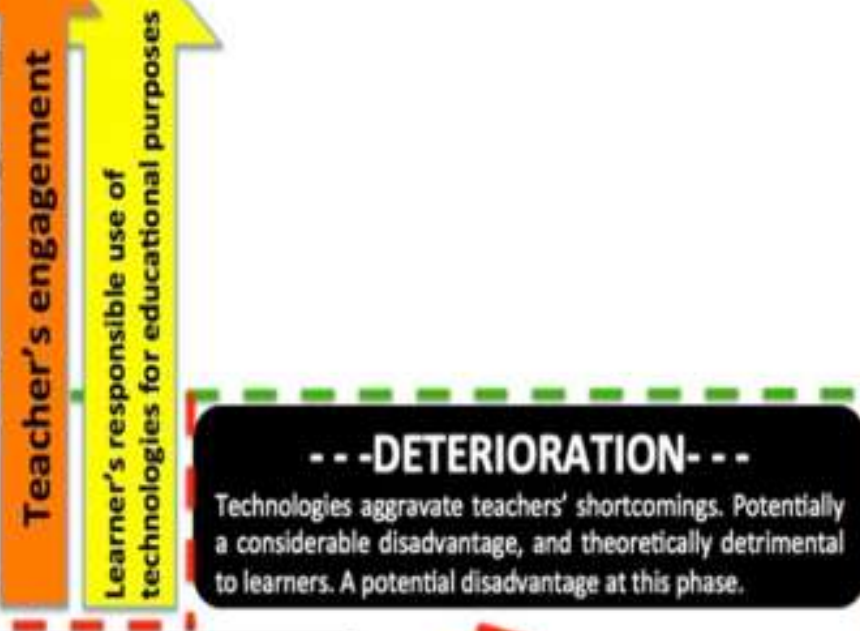

\section{ADOPTION}

Teachers need time in order to fully engage in the

pedagogical uses of technologies in the classroom. A (normal) disadvantage at this phase of adoption.

Figure 1 : ASPID Model 
is an acronym for the five phases of the model, namely: Analysis (analysis), Design (design), Development (development), Implementation (implementation) and evaluation (assessment).

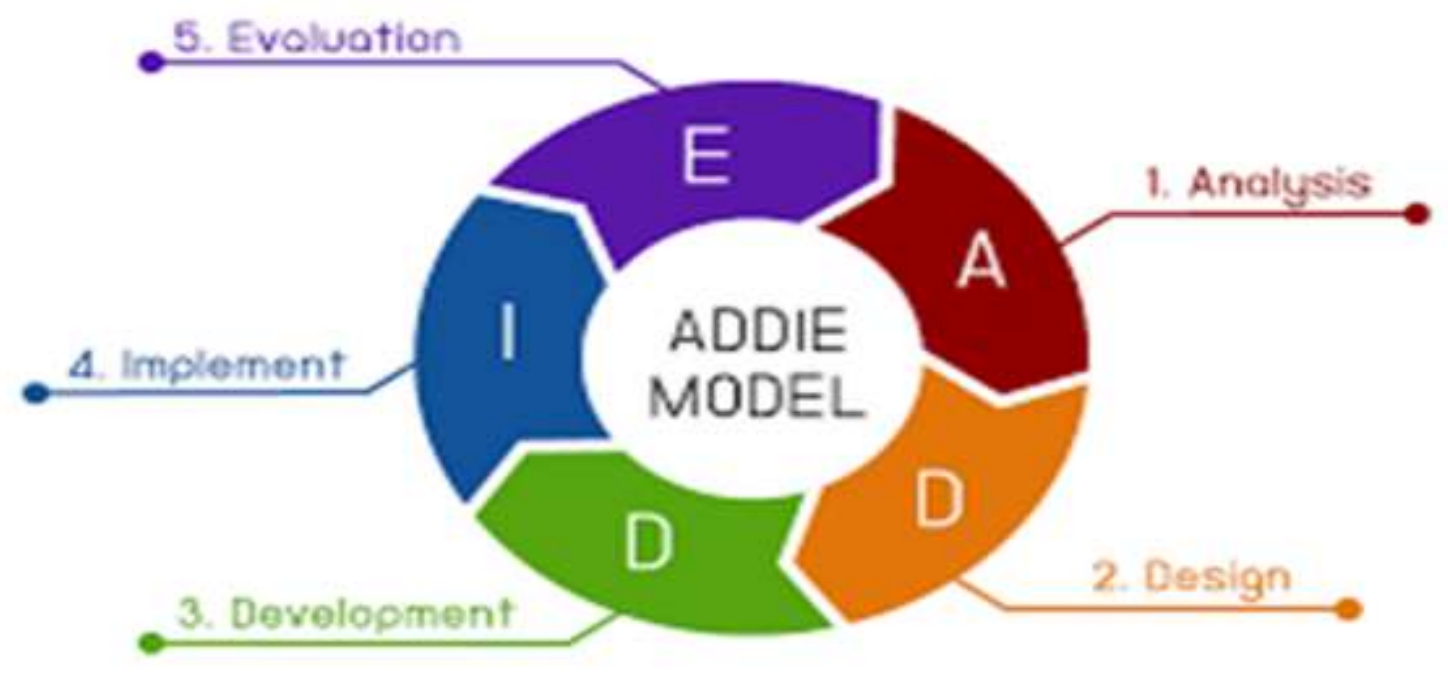

Figure 2 : ADDIE Model

In the analysis phase, instructional problem is clarified, the instructional goals and objectives are established and the learning environment and learner's existing knowledge and skills are identified. Below are some of the questions that are addressed during the analysis phase:

- Who is the audience and their characteristics?

- Identify the new behavioral outcome?

- What types of learning constraints exist?

- What are the delivery options?

- What are the online pedagogical considerations?

- What is the timeline for project completion?

The design phase deals with learning objectives, assessment instruments, exercises, content, subject matter analysis, lesson planning and media selection. The design phase should be systematic and specific. Systematic means a logical, orderly method of identifying, developing and evaluating a set of planned strategies targeted for attaining the project's goals. Specific means each element of the instructional design plan needs to be executed with attention to details.

These are steps used for the design phase:

- Documentation of the project's instructional, visual and technical design strategy

- Apply instructional strategies according to the intended behavioral outcomes by domain (cognitive, affective, psychomotor).

- Create storyboards

- Design the user interface and user experience

- Prototype creation

- Apply visual design (graphic design)

The development phase is where the developers create and assemble the content assets that were created in the design phase. Programmers work to develop and/or integrate technologies. Testers perform debugging procedures. The project is reviewed and revised according to any feedback given.

During the implementation phase, a procedure for training the facilitators and the learners is developed. The facilitators' training should cover the course curriculum, learning outcomes, method of delivery, and testing procedures. Preparation of the learners include training them on new tools (software or hardware), student registration. This is also the phase where the project manager ensures that the books, hands on equipment, tools, CD-ROMs and software are in place, and that the learning application or Web site is functional.

The evaluation phase consists of two parts: formative and summative. Formative evaluation is present in each stage of the ADDIE process. Summative evaluation consists of tests designed for domain specific criterion-related referenced items and providing opportunities for feedback from the users. 


\subsubsection{Simulation models}

As early as the 1970s, the specialized services of UNESCO, the World Bank and the educational planning directorates of a number of countries began to develop different simulation models for the establishment of forecasts. Here we present two categories of approaches that have prevailed in the design of simulation models: the first is that of the generic model and specific applications, the second is that of the budget model and the demographic model [10].

Generic models are sometimes referred to as "ready to wear" models. They consist of designing simulation models that contain elements common to most educational systems. A generic model does not correspond to a given system or country, but represents a virtual educational system. With limited adaptation, it provides rough indications of the pedagogical, physical and financial implications of the broad policy directions. It is therefore useful in a phase of pre-definition of educational policy options. The generic model has the advantage of being operational as soon as basic data and overall objectives are available, but has limitations as a detailed programming tool.

Country specific applications are also called "bespoke" models. A model of specific simulation applications is generally adopted to define more or less detailed options for the development of education, especially in the development phase of development programs or action plans. Applications designed at this stage of post-definition of educational policy take into account the structure and specificities of the educational system of the country concerned. This type of model, adapted to a specific country, cannot be used by another without a deep restructuring and a careful adaptation. A "tailor-made" simulation application, designed on the basis of close collaboration between policy-makers and specialists, reflects the specificities of a country's situation and educational policy, but at the same time requires a certain amount of time. longer development and validation.

In the so-called budget model, the planner is primarily concerned with capping at an acceptable level the proportion of education expenditure relative to the general state budget; the computer then calculates backwards to achieve the schooling goals. In the case of the demographic model, it is an inverse logic that is developed. Considered as independent variables, the objectives of schooling are set a priori and the computer calculates the corresponding financial envelopes that become the consequence. It can be said that the budget model responds to the need for control of education spending, particularly as a result of structural adjustment policies advocated by donors, while the demographic model places the right to education and the satisfaction of social demand in this area at the center of educational policy, therefore at the forefront of government concerns. At the country level, in practice, it is the latter model that has emerged, not only for political reasons, but also for technical reasons relating to the logic of the chain of calculation.

The so-called demographic model has taken precedence over the budget model in that the education policy pursued is concerned with improving quality while increasing access to and participation in education. In this model constructed in the image of the structure of the educational system of a country, the decision variables are mainly the educational objectives and not the budgetary ones. Figure 3 presents the simplified diagram of the flow structure of a simulation model based on a demographic approach [10].

\section{Presentation of a generic meta-model for the applications of e-governance in the field of education}

It's a three-level model:

- Level 1: that of the learners; it is the lowest level; it is the heart of the education system. It is at this level that the problems relating to education are detected and the teachers who accompany the learner on a daily basis are the first to take up these problems. The higher levels ( 2 and 3) have an impact on the latter because everything that happens at these levels influences the learners

- Level 2: that of teachers; it directly influences level 1 because any action taken at this level has a direct impact on it. He is influenced by Level 3 acting on him; at this level the difficulties of learners and teachers are relayed to level 3 for consideration

- Level 3: that of the decision makers. It is at this level that all strategic decisions relating to the education system are made. These decisions depend on the types of difficulties collected and transmitted by level 2. The decision-maker should therefore implements, for example, a sub-model of school construction or training and assignment of teachers or the construction of classrooms according to the informations obtained from the teaching staff. Figure 4 presents the proposed meta-model. 


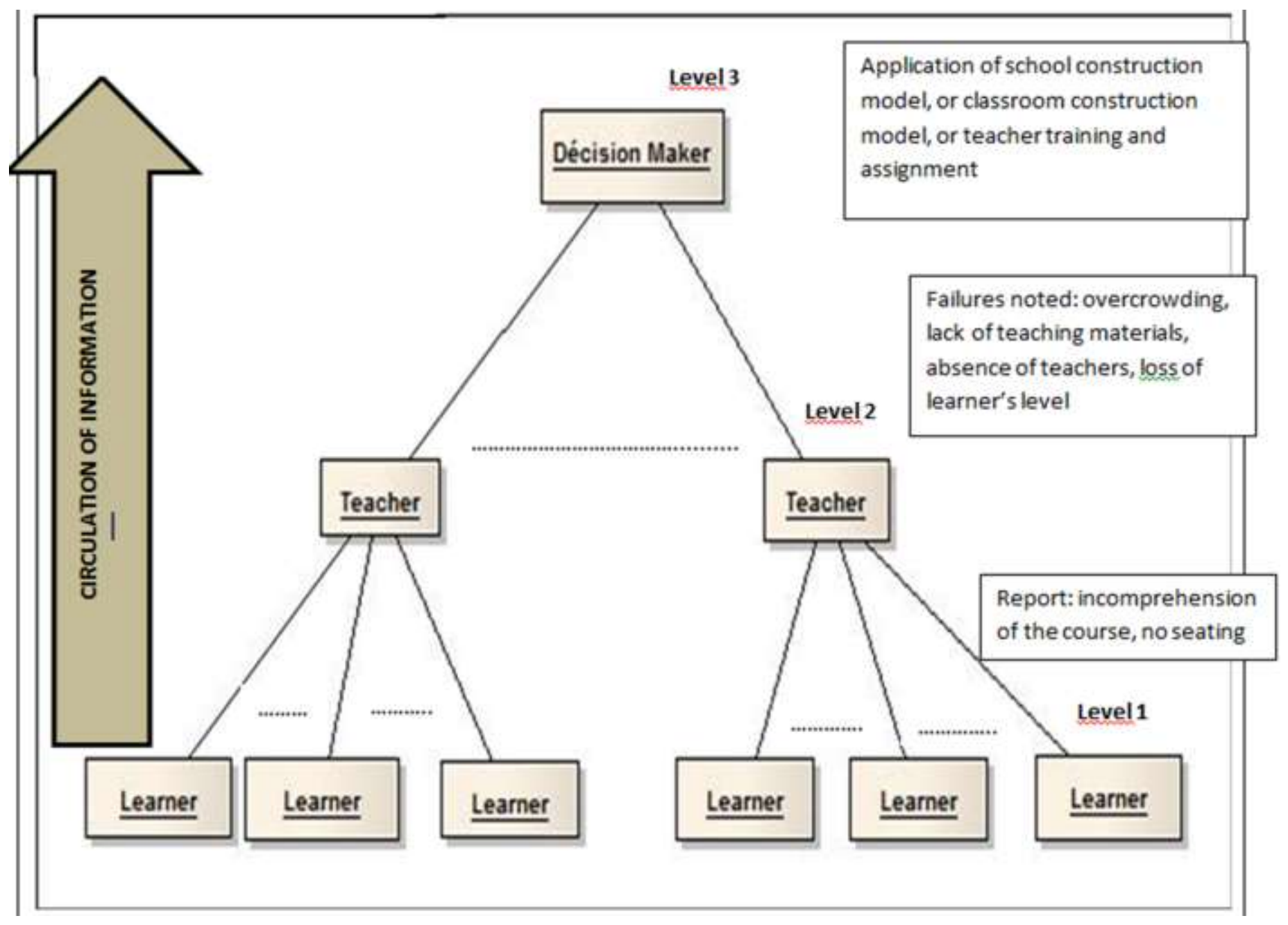

Figure 3: the generic multi-level decisional model for e-governance applications in the educational field

\section{ILLUSTRATION OF THE IMPLEMENTATION OF SUB MODELS}

This part is devoted to the presentation of the neural networks which will be used later to illustrate the sub-models. In this article, we will present the sub-model of school construction.

\subsection{Artificial neural networks}

\subsubsection{Definition}

Many terms are used today in the literature to refer to the domain of artificial neural networks, as connectionism or neuromimetic. For Claude TOUZET, we must associate with each of these names a precise semantics. Connexionism and neuromimetics are both full-fledged research domains, which manipulate each of the models of artificial neural networks, but with different objectives. The goal of connectionist engineers and researchers is to improve computing capabilities by using models with highly connected components. Neuromimetics, for their part, manipulate models of artificial neural networks for the sole purpose of verifying their biological theories of the functioning of the central nervous system.

Neural networks are used to model the functioning of the human brain in the sense that it produces thought using neurons that is the result of cognition from a body of knowledge; Neurons receive signals (electrical impulses) from the dendrites and send the information through the axons. Figure 1 shows a biological neuron. Each has a particular function that can be represented by a mathematical model 


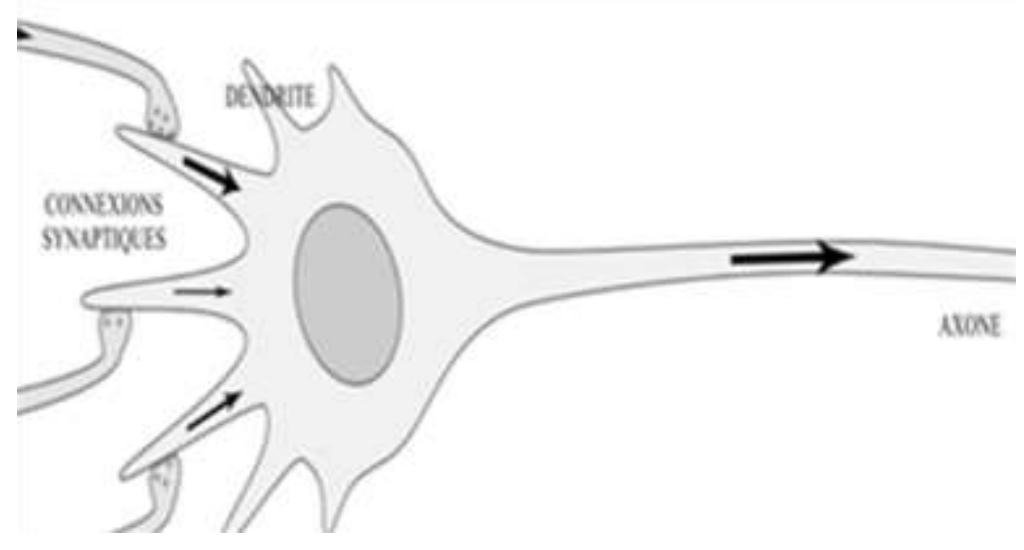

Figure 4: biological Neuron

\subsubsection{Mathematical modeling}

Biological neural networks easily realize a number of applications such as approximation, prediction, pattern recognition, classification, signal processing, learning by example, memorization, generalization. These applications are all the results of efforts in algorithmic and artificial intelligence, at the limit of current possibilities. Artificial neural networks are models, as such they can be described by their components, their descriptive variables and the interactions of the components.

\subsubsection{Structure of an artificial neuron}

Figure 1 shows the structure of an artificial neuron. Each artificial neuron is an elementary computing unit. It receives a variable number of inputs from upstream neurons. Each of these entries is associated with a weight w abbreviation of weight representing the strength of the connection. Each unit of elementary calculus has a single output, which then branches to feed a variable number of downstream neurons. Each connection is associated with a weight. Figure 2 gives the notation used in the representation of a neural network (here three neurons $\mathrm{i}, \mathrm{j}, \mathrm{k}$ ). For the neuron $\mathrm{i}$, the entries are of weight wij whereas the downstream connections are of weight wki.

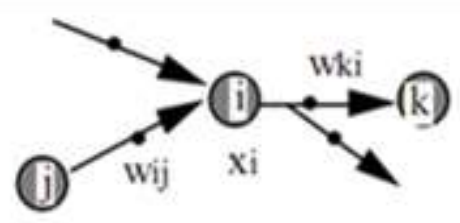

Figure 5: notations used in the representation of a neural network

\subsubsection{Behavior}

There are two phases. The first is usually the calculation of the weighted sum of entries according to the following expression: $\mathrm{a}=\Sigma$ (wi, e i) where wi is the weight of the input ei and has the weighted sum. From the value of a, a transfer function calculates the value of the state of the neuron. It is this value that will be transmitted to downstream neurons. There are many possible forms for the transfer function. The most common are shown in Figure 6 wherein we have a threshold function (S, the value of the threshold); in b, a piecewise linear function; in c a sigmoid. Note that unlike biological neurons whose state is binary, most transfer functions are continuous, offering an infinity of possible values in the interval $[0,+1]($ or $[-1,+1])$.

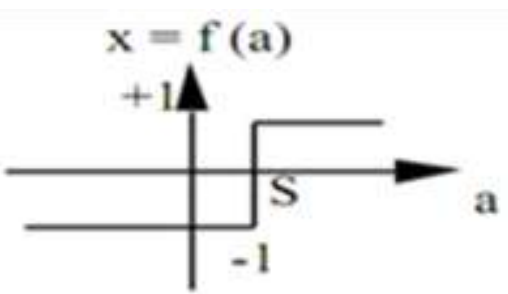

a

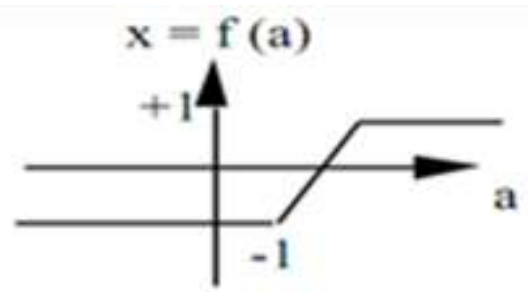

b

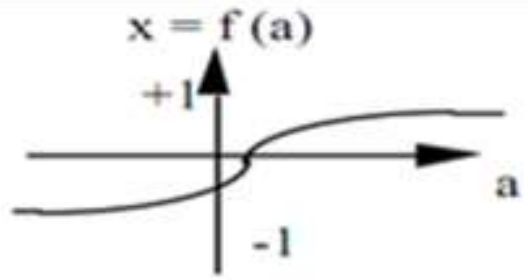

c

Figure 6: Different forms of the transfer 
We note that the equations describing the behavior of artificial neurons do not introduce the notion of time. They are discrete time models, synchronous, whose behavior of the components does not change over time. A set of descriptive variables is used to describe the state of the system. A subset of descriptive variables consists of input variables, variables whose value is determined externally to the model. The connections between the neurons that make up the network describe the topology of the model. The term Perceptron allows to designate a single neuron.

\subsubsection{Perceptron}

The learning having been realized, the weights are fixed. The neuron of figure 7 realizes a simple weighted sum w1.e $1+$ w2 2 where wi is the weight associated with the input ei, compares a threshold value $\mathrm{S}$, and provides a binary response $\mathrm{x}$ at the output. For example, its decision can be interpreted as class 1 if the value of $\mathrm{x}$ is +1 and class 2 if the value of $\mathrm{x}$ is -1 . To determine a neural network it is necessary to find the synaptic coefficients; we are talking about a learning phase.
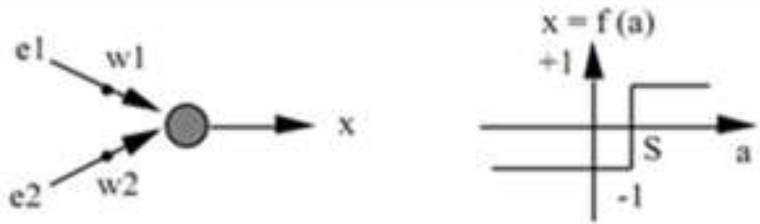

Figure 7: perceptron behavior

\subsubsection{Learning}

Learning is a phase in the development of a neural network during which the behavior of the network is modified until the desired behavior is achieved. Neural learning uses examples of behavior. In the case of artificial neural networks, the learning algorithm is often added to the description of the model. The model without learning is of little interest. In the majority of the current algorithms, the variables modified during the learning are the weights of the connections. Learning is the modification of network weights in order to give the network response to examples and experience. At the level of learning algorithms, two major classes have been defined according to whether learning is supervised or unsupervised. This distinction is based on the form of the learning examples. In the case of supervised learning, the examples are couples (Input, Associated Output) while only the (Input) values are available for unsupervised learning.

\subsubsection{Hebb's law, an example of unsupervised learning}

Hebb's law (1949) applies to connections between neurons, as shown in Figure 5. It is expressed as follows: "If 2 cells are activated at the same time then the strength of the connection increases". The change in weight depends on the coactivation of the presynaptic and postsynaptic neurons, as shown in Table 1 . xi and $x j$ are respectively the activation values of the neurons $i$ and $j$, $\partial w i j$ (partial derivative of the weight) corresponds to the modification weight achieved.

\begin{tabular}{|l|l|l|}
\hline$x i$ & $x j$ & $\partial w \mathbf{j}$ \\
\hline $\mathbf{0}$ & $\mathbf{0}$ & $\mathbf{0}$ \\
\hline 0 & 1 & 0 \\
\hline 1 & 0 & 0 \\
\hline 1 & 1 & + \\
\hline
\end{tabular}

Table 1: Hebb's law

Hebb's law can be modeled by the following equations:

- $\quad$ wij $(\mathrm{t}+1)=\mathrm{w}$ ij $(\mathrm{t})+\partial \mathrm{wij}(\mathrm{t})$ where wij $(\mathrm{t}+1)$ is the new weight, wij $(\mathrm{t})$ the old,

- $\quad \partial \mathrm{wij}(\mathrm{t})=\mathrm{xi} . \mathrm{x} \mathrm{j}$ the coactivity is modeled as the product of the two activation values)

The learning algorithm modifies iteratively (little by little) the weights to adapt the response obtained to that desired. It's really about changing the weights when there's only an error. It is as follows:

1 / Initialization of the weights and the threshold $S$ to values (small) chosen at random.

2 / Presentation of an entry $\mathrm{El}=(\mathrm{e} 1, \ldots \mathrm{e} n)$ of the learning base.

3 / Calculation of the obtained output $x$ for this input: $a=\Sigma$ (w i .e i) - S

$\mathrm{x}=\operatorname{sign}(\mathrm{a})($ if $\mathrm{a}>0$ then $\mathrm{x}=+1$, otherwise $\mathrm{a} \leq 0$ then $\mathrm{x}=-1$ )

4 / If the output $x$ is different from the desired output $\mathrm{dl}$ for this input example El then modification of the weights ( $\mu$ is a positive constant, which specifies the step of modification of the weights): wij $(t+1)=w i j(t)+\mu(x i x j)$

5 / As long as all the examples of the learning base are not processed correctly (i.e. change of weights), return to step 2. 


\subsubsection{Application example of the Hebb learning algorithm}

Let's choose for neurons a binary behavior. The inputs e 1 and e 2 are considered as neurons. We will do the learning on a very simple problem. The learning base is described by Table 2 :

\begin{tabular}{|l|l|l|}
\hline $\mathrm{e} 1$ & $\mathrm{e} 2$ & $\mathrm{X}$ \\
\hline 1 & 1 & 1 \\
\hline 1 & -1 & 1 \\
\hline-1 & 1 & -1 \\
\hline-1 & -1 & -1 \\
\hline
\end{tabular}

Table 2: base of learning examples for the Hebb's law

1 / Initial conditions: $\mu=+1$, weights and threshold are zero.

2 / Calculate the value of $\mathrm{x}$ for example (1):

$3 / \mathrm{a}=$ w1.e $1+\mathrm{w} 2 . \mathrm{e} 2-\mathrm{S}=0.0 * 1+0.0 * 1-0.0=0$

$\mathrm{a} \leq 0=\mathrm{x}=-1$

4 / The output is wrong, so you have to change the weights by applying:

$\mathrm{w} 1=\mathrm{w} 1+\mathrm{e} 1 . \mathrm{x}=0 * 0+1 * 1=1$

$\mathrm{w} 2=\mathrm{w} 2+\mathrm{e} 2 \cdot \mathrm{x}=0 * 0+1 * 1=1$

2 / We go on to the following example (2):

$3 / \mathrm{a}=1 * 1+1 *-1-0.0=0$

$\mathrm{a} \leq 0=\mathrm{x}=-1$

4 / The output is wrong, so you have to change the weights by applying:

$\mathrm{w} 1=1+1 * 1=2$

$\mathrm{w} 2=1+1 *-1=0$

The following example (3) is correctly processed: $a=-2$ and $x=-1$ (the output is good). We pass directly, without changing the weights in Example (4). This one too is correctly treated. We then return to the beginning of the learning base: example (1). It is correctly treated, as well as the second (2). The learning algorithm is now complete: the entire learning base has been reviewed without changing the weights.

Question: Let the network consist of 4 input neurons and one output neuron $(w 1=w 2=w 3=w 4=S=0)$ and the learning base:

\begin{tabular}{|l|l|l|l|l|}
\hline $\mathrm{e} 1$ & $\mathrm{e} 2$ & $\mathrm{e} 3$ & $\mathrm{e} 4$ & $\mathrm{x}$ \\
\hline 1 & -1 & 1 & -1 & 1 \\
\hline 1 & 1 & 1 & 1 & 1 \\
\hline 1 & 1 & 1 & -1 & -1 \\
\hline 1 & -1 & -1 & 1 & -1 \\
\hline
\end{tabular}

Table 3: learning base for the question

Answer: This learning algorithm does not solve this problem.

We are not able to express a combination of activations correlated with the output. However, there are solutions such as $(\mathrm{w} 1=-$ $0.2, \mathrm{w} 2=-0.2, \mathrm{w} 3=0.6, \mathrm{w} 4=0.2)$. An efficient calculation algorithm for this problem is Perceptron model learning.

\subsubsection{The Perceptron Learning Rule, an example of supervised learning}

The rule of Hebb does not apply in certain cases, although a solution exists (cf exercise of the preceding paragraph). Another learning algorithm has been proposed, which takes into account the error observed at the output.

The Perceptron learning algorithm is similar to that used for Hebb's law. The differences are in the change of weights.

1 / Initialization of the weights and the threshold $\mathrm{S}$ to values (small) chosen at random.

2 / Presentation of an entry $\mathrm{El}=(\mathrm{e} 1, \ldots \mathrm{e} \mathrm{n})$ of the learning base.

3 / Calculation of the obtained output $x$ for this input: $a=\Sigma$ (wi. E i) - S

$\mathrm{x}=\operatorname{sign}(\mathrm{a})$ (if $\mathrm{a}>0$ then $\mathrm{x}=+1$, otherwise $\mathrm{a} \leq 0$ then $\mathrm{x}=-1$ )

4 / If the output $x$ of the Perceptron is different from the desired output dl for this input example

El then modification of the weights ( $\mu$ the step of modification): wi $(t+1)=w i(t)+\mu *((d-x) * e i)$

Reminder: $\mathrm{d} l=+1$ if $E$ is of class $1, \mathrm{~d} l=-1$ if $E$ is of class 2 and $(\mathrm{d} l-\mathrm{x})$ is an estimate of the error.

5 / As long as all the examples of the learning base are not processed correctly (i.e. change of weights), return to step 2. 


\subsubsection{Example of how the Perceptron learning algorithm works:}

Base of learning examples:

\begin{tabular}{|l|l|l|}
\hline $\mathrm{e} 1$ & $\mathrm{e} 2$ & $\mathrm{X}$ \\
\hline 1 & 1 & 1 \\
\hline-1 & 1 & -1 \\
\hline-1 & -1 & -1 \\
\hline 1 & -1 & -1 \\
\hline
\end{tabular}

Table 4: base of learning examples for the perceptron learning algorithm

$1 /$ Initial conditions: $\mathrm{w} 1=-0.2, \mathrm{w} 2=+0.1, \mathrm{~S}=0.2,(\mu=+0.1)$

$2 / \mathrm{a}(1)=-0.2+0.1-0.2=-0.3$

$3 / \mathrm{x}(1)=-1$ (the desired output $\mathrm{d}(1)=+1$, hence the change in weights)

$4 / \mathrm{w} 1=-0.2+0.1 *(1+1) *(+1)=0, \mathrm{w} 2=+0.1+0.1 *(1+1) *(+1)=+0.3$

$2 / \mathrm{a}(2)=+0.3-0.2=+0.1$

$3 / \mathrm{x}(2)=+1$ (the desired output $\mathrm{d}(1)=-1$, hence the change in weights)

$4 / \mathrm{w} 1=0+0.1 *(-1-1) *(-1)=+0.2, \mathrm{w} 2=+0.3+0.1 *(-1-1) *(+1)=+0.1$

$2-3 / \mathrm{a}(3)=-0.2-0.1-0.2=-0.5 \mathrm{Ok}$

$2-3 / \mathrm{a}(4)=+0.2-0.1-0.2=-0.1 \mathrm{Ok}$

$2-3 / \mathrm{a}(1)=+0.2+0.1-0.2=+0.1 \mathrm{Ok}$

$2-3 / \mathrm{a}(2)=-0.2+0.1-0.2=-0.1 \mathrm{Ok}$

5 / All the examples of the database have been correctly processed, the learning is finished.

The Perceptron partitions its input space into 2 classes (1 and 2) according to the value of its output $(+1$ or -1$)$. The separation of these two zones is carried out by a hyperplane (Fig. 3 ) . The equation of the separating line is: w1.e $1+\mathrm{w} 2$.e $2-\mathrm{S}=$ 0

\subsection{The sub-model of construction of an institution based on the perceptron algorithm}

As inputs of the sub-model we have:

eDEU: DEU distance separating the place of the school from the urban locality

eDLU: distance DLU separating the place of the high school from the urban locality

eDUU: DUU distance separating the location of the university from the urban locality

eDER: distance DER separating the place of the school from the rural locality

eDLR: distance DLR separating the place of the school from the rural locality

eDUR: distance DUR separating the location of the university from the rural locality

eEE: availability of teachers for school

eEL: availability of high school teachers

ePNE: availability of non-teaching staff for school

ePNL: availability of non-teaching staff for high school

eEU: availability of university teachers

ePNU: availability of non-teaching staff at the university

eT: type of relief of the place of construction

eZU: urban area

eZR: rural area

eFER: FER finances needed to build a school in rural areas

eFEU: FIRE finances needed to build a school in urban areas

eFLR: FLR finances needed to build high school in rural areas

eFLU: FLU finances needed to build a high school in urban areas

eFUR: FUR finances needed to build a university in rural areas

eFUU: FUU finances needed to build a university in urban areas

eEXSIL: NSIL number of students who cannot register at SIL in the locality

eEXCP: NCP number of students who do not have the opportunity to register at the CP in the locality

eEXCE1: NCEI number of students who cannot register at the IRC in the locality

eEXCE2: NCEII number of students who do not have the opportunity to register with the CEII in the locality

eEXCM1: NCMI number of students not able to enroll in the CMI in the locality

eEXCM2: NCMII number of students who cannot register at the CMII in the locality

eEXSIX: NSIX number of students who do not have the opportunity to enroll in Sixth in the locality 
eEXCINQ: NCINQ number of students who do not have the possibility to register in the Fifth in the locality

eEXQUAT: NQUAT number of pupils who do not have the possibility to register in the Fourth in the locality

eEXTROIS: number of pupils who do not have the possibility to register in the third place

eEXSEC: NSEC number of students who do not have the opportunity to enroll in Second in the locality

eEXPRE: Number of students not eligible to register in the locality

eEXTER: NTER number of students who do not have the possibility to register in Terminal in the locality

ePRUn: PRUn population of the rural area seeking registration in a sector

ePUUn: PUUn population of the urban area in search of an inscription to a die

eFRUn: FRUn finances needed to have a university in rural areas

eFUUn: FUUn finances needed to have a university in urban areas

eFe-LEARN: the Fe-LEARN finances needed for setting up an e-learning platform in the university

ee-LEARN: the set of conditions for e-learning, namely: The region where the learners reside (language of learning), the prior knowledge of the learners on the subject, the technical skills of the learners in the field of computer science, time available for digital learning and learning context, where learners will take the e-learning course, network bandwidth, software and computer capabilities available to the learner

$\mathrm{eDEU}=1$ if distance $\mathrm{DE} \leq$ Dmax-locality-school location and $\mathrm{eDE}=-1$ otherwise

$\mathrm{eDLU}=1$ if distance DL $\leq$ Dmax-locality-place of high school and eDL $=-1$ otherwise

$\mathrm{eDUU}=1$ if distance $\mathrm{DU} \leq \mathrm{Dmax}$-locality-location of the university and $\mathrm{eDU}=-1$ otherwise

$\mathrm{eT}=1$ if non-swampy accessible area and $\mathrm{eT}=-1$ otherwise

$\mathrm{eZR}=1$ if the zone is rural and $\mathrm{eZR}=-1$ otherwise

$\mathrm{eZU}=1$ if the zone is urban and $\mathrm{eZU}=-1$ otherwise

$\mathrm{eEE}=1$ if availability of teachers for school and $\mathrm{eEE}=-1$ otherwise

$\mathrm{eEL}=1$ if availability of high school teachers and $\mathrm{eEL}=-1$ otherwise

$\mathrm{ePNE}=1$ if availability of non-teaching staff for school and ePNE $=-1$ otherwise

$\mathrm{ePNL}=1$ if availability of non-teaching staff for high school and ePNL $=-1$ otherwise

$\mathrm{eEU}=1$ if availability of university teachers and eEU $=-1$ otherwise

ePNU $=1$ availability of non-teaching staff of the university and ePNU $=-1$ otherwise

$\mathrm{eFEU}=1$ if finance FEU $\geq$ FEUSeuil and eFEU $=-1$ otherwise

$\mathrm{eFLU}=1$ if finance FLU $\geq$ FLUSeuil and eFLU $=-1$ otherwise

eFUU $=1$ if finances FUU $\geq$ FUUSeuil and $\mathrm{eFUU}=-1$ otherwise

$\mathrm{eFER}=1$ if the finances FER $\geq$ FERSeuil and eFER $=-1$ otherwise

eFLR $=1$ if FLR finances $\geq$ FLRSeuil and $\mathrm{eFLR}=-1$ otherwise

eFUR $=1$ if finance FUR $\geq$ FURSeuil and eFUR $=-1$ otherwise

eEXSIL $=1$ if NSIL $\geq$ EXSILSeuil and eEXSIL $=-1$ otherwise

$\mathrm{eEXCP}=1$ if existing $\mathrm{NCP} \geq \mathrm{EXCPSeuil}$ and $\mathrm{eEXCP}=-1$ otherwise

eEXCE1 $=1$ if NCEI $\geq$ EXCE1Seuil and eEXCE1 $=-1$ otherwise

eEXCE2 $=1$ if NCEII $\geq$ EXCE2Seuil and eEXCE2 $=-1$ otherwise

eEXCM1 $=1$ if NCMI $\geq$ EXCM1Shreshold and eEXCM1 $=-1$ otherwise

eEXCM2 $=1$ if NCMII $\geq$ EXCM2Seuil and eEXCM2 $=-1$ otherwise

eEXSIX $=1$ if NSIX $\geq$ EXSIXSeuil and eEXSIX $=-1$ otherwise

$\mathrm{eEXCINQ}=1$ if NCINQ $\geq$ EXCINQSeuil and eEXCINQ $=-1$ otherwise

eEXQUAT $=1$ if NQUAT $\geq$ EXQUATSeuil and eEXQUAT $=-1$ otherwise

eEXTROIS $=1$ if NTROIS $\geq$ EXTROISSeuil and eEXTROIS $=-1$ otherwise

eEXSEC $=1$ if NSEC $\geq$ EXSECSeuil and eEXSEC $=-1$ otherwise

eEXPRE $=1$ if NPRE $\geq$ EXPRESeuil and eEXPRE $=-1$ otherwise

eEXTER $=1$ if NTER $\geq$ EXTERSeuil and eEXTER $=-1$ otherwise

eFUUn $=1$ if finances FUUn $\geq$ FUUnSeuil and eFUUn $=-1$ otherwise

eFRUn $=1$ if the finances FRUn $\geq$ FRUnSeuil and eFRUn $=-1$ otherwise

eFe-LEARN $=1$ if finances Fe-LEARN $\geq$ Fe-LEARNSeuil and eFe-LEARN $=-1$ otherwise

ee-LEARN = 1 if all the conditions mentioned above are met with good bandwidth and ee-LEARN $=-1$ otherwise

Let $\mathrm{E} 1$ be the main input obtained from the secondary inputs eDEU, eT, eFEU, eZU, eDER, eZR;

$\mathrm{E} 1=(\mathrm{eDE}$ and eFEU eZU eEE ePNE) $\vee(\mathrm{eDER}$ eFer eZR eEE ePNE)

$\mathrm{E} 1=1$ if $\mathrm{eDEU}=1$ and $\mathrm{eT}=1$ and $\mathrm{eFEU}=1$ and $\mathrm{eZU}=1$ and $\mathrm{eEE}=1$ and $\mathrm{ePNE}=1$ or $\mathrm{eDER}=1$ and $\mathrm{eT}=1$ and $\mathrm{eFER}=1$ and

$\mathrm{eZR}=1$ and $\mathrm{eEE}=1$ and $\mathrm{ePNE}=1$; 
$\mathrm{E} 1=-1$ if $\mathrm{eDEU}=-1$ or $\mathrm{eT}=-1$ or $\mathrm{eFEU}=-1$ or $\mathrm{eZU}=-1$ or $\mathrm{eEE}=-1$ or $\mathrm{ePNE}=-1$ and $\mathrm{eDER}=-1$ or $\mathrm{eT}=-1$ or $\mathrm{eFER}=-1$ or $\mathrm{eZU}=-1$ or $\mathrm{eEE}=-1$ or $\mathrm{ePNE}=-1$

Let $\mathrm{E} 2=$ eEXSIL $\vee$ eEXCP $\vee$ eEXCE1 $\vee$ eEXCE2 $\vee$ eEXCM1 $\vee$ eEXCM2

$\mathrm{E} 2=1$ if $\mathrm{eEXSIL}=1$ or $\mathrm{eEXCP}=1$ or $\mathrm{eEXCE} 1=1$ or $\mathrm{eEXCE} 2=1$ or $\mathrm{eEXCM} 1=1$ or $\mathrm{eEXCM} 2=1$

$\mathrm{E} 2=-1$ otherwise

E3 is obtained from the following subentries: eDLU, eT, eFLU, eZU, eDLR, eZR, eFLR;

$\mathrm{E} 3=(\mathrm{eDLU}$ and eFLU eZU eEL ePNL) $\vee($ eDLR and eFLR eZR eEL ePNL)

$\mathrm{E} 3=1$ if $\mathrm{eDLU}=1$ and $\mathrm{eT}=1$ and $\mathrm{eFLU}=1$ and $\mathrm{eZU}=1$ and $\mathrm{eEL}=1$ and $\mathrm{ePNL}=1$ and $\mathrm{eDLR}=1$ and $\mathrm{eT}=1$ and $\mathrm{eFLR}=1$ and $\mathrm{eZR}=1$ and $\mathrm{eEL}=1$ and $\mathrm{ePNL}=1$

$\mathrm{E} 3=-1$ if $\mathrm{eDLU}=-1$ or $\mathrm{eT}=-1$ or $\mathrm{eFLU}=-1$ or $\mathrm{eZU}=-1$ or $\mathrm{eEL}=-1$ or $\mathrm{ePNL}=-1$ and $\mathrm{eDLR}=-1$ or $\mathrm{eT}=-1$ or $\mathrm{eFLR}=-1$ or $\mathrm{eZU}=-1$ or $\mathrm{eEL}=-1$ or $\mathrm{ePNL}=-1$

E4 is obtained from the following subentries: eEXSIX, eEXQUAT, eEXTROIS, eEXSEC, eEXPRE, eEXTER

E4 $=$ eEXSIX $\vee$ eEXCINQ $\vee$ eEXTRATE EX eEXTROIS $\vee$ eEXSEC $\vee$ eEXPRE $\vee$ eEXTER

$\mathrm{E} 4=1$ if $\mathrm{eEXSIX}=1$ or $\mathrm{eEXCINQ}=1$ or $\mathrm{eEXQUAT}=1$ or $\mathrm{eEXTROIS}=1$ or eEXSEC $=1$ or $\mathrm{eEXPRE}=1$ or $\mathrm{eEXTER}=1$

$\mathrm{E} 4=-1$ otherwise

E5 is obtained from the following subentries: eDUR, eDUU, eFUUn, eFRUn, eT, eZU, eZR, eFe-LEARN, ee-LEARN

$\mathrm{E} 5=($ eDUU eFUUn eZU eEU eUU ePUU) $\vee($ eDUr and EFRUn eZR eEU ePUU) $\vee($ eDUU eTUUnE eZU eEU ePNU eFeLEARN ee-LEARN ) E (eDUr and eFRUn eZR eEU ePNU eFe-LEARN ee-LEARN)

$\mathrm{E} 5=1$ if $\mathrm{eDUU}=1$ and $\mathrm{eT}=1$ and $\mathrm{eFUUn}=1$ and $\mathrm{eZU}=1$ and $\mathrm{eEU}=1$ and $\mathrm{ePNU}=1$ or if $\mathrm{eDUR}=1$ and $\mathrm{eT}=1$ and $\mathrm{eFRUn}=$ 1 and $\mathrm{eZR}=1$ and $\mathrm{eEU}=1$ and $\mathrm{ePNU}=1$ or $\mathrm{eDUU}=1$ and $\mathrm{eT}=1$ and $\mathrm{eFUUn}=1$ and $\mathrm{eZU}=1 \mathrm{eEU}=1$ and $\mathrm{ePNU}=1$ and $\mathrm{eFe}-$ LEARN $=1$ and ee-LEARN $=1$ or eDUR $=1$ and $\mathrm{eT}=1$ and eFRUn $=1$ and $\mathrm{eZR}=1$ and $\mathrm{eEU}=1$ and $\mathrm{ePNU}=1$ and $\mathrm{eFe}-$ LEARN $=1$ and ee-LEARN $=1$

$\mathrm{E} 5=-1$ otherwise

E6 is obtained from the following subentries: ePRUn, ePUUn

E6 $=$ ePRUn $\vee$ ePUUn

$\mathrm{E} 6=1$ if $\mathrm{ePRUn}=1$ or ePUUn $=1$

$\mathrm{E} 6=-1$ if $\mathrm{ePRUn}=-1$ and $\mathrm{ePUUn}=-1$

Base of learning examples:

\begin{tabular}{|l|l|l|l|l|l|l|l|l|}
\hline \multicolumn{5}{|c|}{ INPUTS } & \multicolumn{3}{c|}{ OUTPUTS } \\
\hline E1 & E2 & E3 & E4 & E5 & E6 & X & Y & Z \\
\hline-1 & -1 & -1 & -1 & -1 & -1 & -1 & -1 & -1 \\
\hline-1 & 1 & -1 & 1 & -1 & 1 & -1 & -1 & -1 \\
\hline 1 & -1 & 1 & -1 & 1 & -1 & -1 & -1 & -1 \\
\hline 1 & 1 & 1 & 1 & 1 & 1 & 1 & 1 & 1 \\
\hline
\end{tabular}

Table 5: base of learning examples of the sub-model of school construction

$\mathrm{X}, \mathrm{Y}, \mathrm{Z}$ are the respective outputs of the perceptrons $1,2,3$

Learning for the perceptron 1

$1 /$ Initial conditions: $\mathrm{w} 11=0.4, \mathrm{w} 12=0.4, \mathrm{w} 13=-0.1, \mathrm{w} 14=-0.1, \mathrm{w} 15=-0.1, \mathrm{w} 16=-0.1 \mathrm{~S}=0.1,(\mu=+0.1)$ on the inputs E1, E2, E3, E4, E5, E6 for an output $\mathrm{X}$ with the activation function $F(x)=\left\{\begin{array}{c}1 \text { if } x>0 \\ -1 \text { otherwise }\end{array}\right.$

2 / a1 $(1)=0.4 *(-1)+(0.4) *(-1)+(-0.1) *(-1)+(-0.1) *(-1)+(-0.1) *(-1)+(-0.1) *(-1)-0.1=-0.5 \mathrm{x}=$ -1 ; the desired output is -1

$3 / \mathrm{a} 1(2)=0.4 *(-1)+(0.4) *(1)+(-0.1) *(-1)+(-0.1) *(1)+(-0.1) *(-1)+(-0.1) *(1)-0.1=-0.1 \mathrm{x}=-1$; the desired output is -1

$4 /$ a1 $(3)=0.4 *(1)+(0.4) *(-1)+(-0.1) *(1)+(-0.1) *(-1)+(-0.1) *(1)+(-0.1) *(-1)-0.1=-0.1 \times=-1$; the desired output is -1 ,

$5 /$ a1 $(4)=(0.4) * 1+(0.4) * 1+(-0.1) * 1+(-0.1) * 1+(-0.1) * 1+(-0.1) * 1-0.1=0.3 \mathrm{x}=1$ : the desired output is 1

6 / All the examples in the database have been correctly processed, the learning is finished.

Learning for the perceptron 2 
1 / We apply the same perceptron learning algorithm with the following initial conditions: $w 21=-0.1$, w22 = $0.1, \mathrm{w} 23=0.4, \mathrm{w} 24=0.4, \mathrm{w} 25=-0.1, \mathrm{w} 26=-0.1 \mathrm{~S}=0.1,(\mu=+0.1)$ on the inputs E1, E2, E3, E4, E5, E6 for a Y output with the activation function $F(x)=\left\{\begin{array}{r}1 \text { if } x>0 \\ -1 \text { otherwise }\end{array}\right.$

$2 / \mathrm{a} 2(1)=(-0.1) *(-1)+(-0.1) *(-1)+(0.4) *(-1)+(0.4) *(-1)+(-0.1) *(-1)+(-0.1) *(-1)-0.1=-0.5 \mathrm{Y}$ $=-1$; the desired output is -1

$3 / \mathrm{a} 2(2)=(-0.1) *(-1)+(-0.1) *(1)+(0.4) *(-1)+(0.4) *(1)+(-0.1) *(-) 1)+(-0.1) *(1)-0.1=-0.1 \mathrm{Y}=-$ 1 ; the desired output is -1

$4 / \mathrm{a} 2(3)=(-0.1) *(1)+(-0.1) *(-1)+(0.4) *(1)+(0.4) *(-1)+(-0.1) *(1))+(-0.1) *(-1)-0.1=-0.1 \mathrm{Y}=$ -1 ; the desired output is -1 ,

$5 / \mathrm{a} 2(4)=(-0.1) * 1+(-0.1) * 1+(0.4) *(1)+(0.4) *(1)+(-0.1) * 1+(-0.1) * 1-0.1=0.3 \mathrm{x}=1$ : the desired output is 1

6 / All the examples in the database have been correctly processed, the learning is finished.

Learning for the perceptron 3

$1 /$ We apply the same perceptron learning algorithm with the following initial conditions: $w 31=-0.1, w 32=-$ $0.1, \mathrm{w} 33=-0.1, \mathrm{w} 34=-0.1, \mathrm{w} 35=0.4, \mathrm{w} 36=0.4, \mathrm{~S}=0.1,(\mu=+0.1)$ on the output $\mathrm{Z}$ with the activation function $F(x)=\left\{\begin{array}{c}1 \text { if } x>0 \\ -1 \text { otherwise }\end{array}\right.$

$2 / \mathrm{a} 3(1)=(-0.1) *(-1)+(-0.1) *(-1)+(-0.1) *(-1)+(-0.1) *(-1)+(0.4) *(-1)+(0.4) *(-1)-0.1=-0.5$ $\mathrm{Z}=-1$; the desired output is -1

$3 / \mathrm{a} 3(2)=(-0.1) *(-1)+(-0.1) *(1)+(-0.1) *(-1)+(-0.1) *(1)+(0.4) *(-1)+(0.4) *(1)-0.1=-0.1 \mathrm{Z}=-$ 1 ; the desired output is -1

$4 / \mathrm{a} 3(3)=(-0.1) *(1)+(-0.1) *(-1)+(-0.1) *(1)+(-0.1) *(-1)+(0.4) *(1)+(0.4) *(-1)-0.1=-0.1 \mathrm{Z}=$ $-1$

$5 /$ a3 $(4)=(-0.1) * 1+(-0.1) * 1+(-0.1) * 1+(-0.1) * 1+(0.4) * 1+(0.4) * 1-0.1=0.3 \mathrm{Z}=1$ : the desired output is 1

6 / All the examples of the database have been correctly processed, the learning is finished

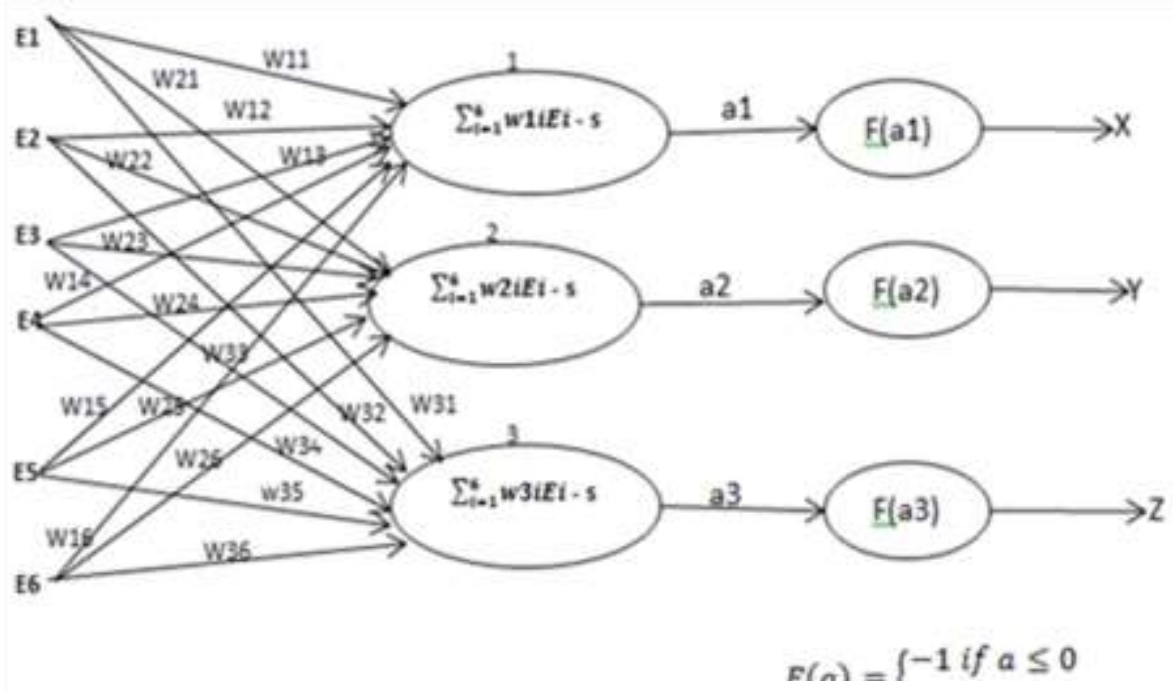

Figure 8 : school construction sub model based on neural network

\section{CONCLUSION AND PERSPECTIVES}

In conclusion, we were talking about presenting a generic model for e-governance applications. We first showed the importance of ICT for the implementation of e-governance, then we presented the benefits of e-governance for a country. The next step was to present the different models that exist in the field of e-governance in education. 
Given the scope of the work to be done, we have chosen in this article to present a meta-model that will serve as a guide to achieve our goal. The meta-model that we presented is subdivided into several sub-models namely: a submodel of assignment of teaching staff and non-teaching staff, a submodel of teachers to be trained and non-teaching staff to recruit ; these will enable optimal management of human resources. For the improvement of the management of financial resources, the meta-model presents a submodel of construction of a classroom, of an Amphi or of a laboratory and a sub-model of construction of a school, from a high school or university. For the improvement of the management of the didactic material it presents a sub-model of allocation of didactic material and tables-benches; a sub-model for assessing the general level of learners (pupils / students) from the submodel of the learner level assessment of each school, high school or university.

In perspective, we intend for the following, to make a detailed presentation of each submodel and experiments from multiagent simulations supported by GIS.

\section{REFERENCES}

[1] An attempt to define the concept of governance, Darine BAKKOUR, December 2013

[2] Governance: Exploring a Definition, Isabelle Lacroix and Pier-Olivier St-Arnaud, University of Sherbrooke, Vol. IV, Number 3, Fall 2012

[3] The five fundamental principles of governance and their implication for international cooperation, Charles Léopold Mayer Foundation for the Progress of Humankind,

[4] e-governance, state-citizen relations in the digital age, Panorama, Issues and perspectives in Africa, Performance Management Consulting, April 2009

[5] Are there (really) information technologies ?, Y. Jeanneret, Septentrion, 2000, p. 59.

[6] Right to Education, Understanding the Right to Education for Children, Humanium, May 2016

[7] Reflecting on the Functions Attributed to ICT in University Teaching, Josianne Basque, 2005

[8] E-government: which governance? Mr Abdellatif MOUATADID, 18 December 2014

[9] ASPID Model, Karsenti, 2014, v0.92

[10] Planning of education through computer simulation, G.-C. Chang and M. Radi, 2001

[11] Training module on financial simulation models in education for the World Bank Institute, Alain Mingat; AFTHD / PSAST; World Bank Mathieu Brossard; Pole de Dakar, French Cooperation / BREDA October 2003. 